\title{
How Small and Medium Enterprises are Using Social Networks? Evidence from the Algarve Region
}

\author{
Ana Belo ${ }^{1}$, Guilherme Castela ${ }^{2}$, Silvia Fernandes ${ }^{2}$ \\ ${ }^{1}$ SandoGago Inc., Portugal \\ ${ }^{2}$ Research Centre for Spatial and Organizational Dynamics (Cieo) \\ Faculty of Economics, University of Algarve, 8005-139 Faro, Portugal \\ anagagobelo@hotmail.com, gcastela@ualg.pt, sfernan@ualg.pt
}

\begin{abstract}
The evolution of internet created new opportunities for small and medium enterprises (SME), among which are social networks. This work aims at analyzing the potential of these networks for the SME in Algarve, creating a questionnaire for the purpose. The empirical study revealed that some firms have already an integrated business strategy with social networks, as well as a group in the firm responsible for it. Most of their managers consider that social networks enhance performance, but few really measure these results. A categorical principal component analysis identified two dimensions of social networks' use: social networks for product-client interaction and knowledge; and social networks with potential for marketing. A supplementary analysis (hierarchical clustering) identified three patterns of SME's involvement in social networks: cluster Social Net Level 1, cluster Social Net Level 2 and cluster Social Net Level 3. These groups validated the results described above, indicating a sustainable methodological approach.
\end{abstract}

Keywords: social networks, SME, patterns, performance, alignment.

\section{Introduction}

Modern drivers of change have led to new features for sustaining business competitiveness: virtual enterprises, creative design, social networks, mobile platforms, etc. These responses require IT-based tools, the increase of information content and creative teams. Any enterprise that wants to optimize its success in the information society must have a basic awareness and a strategy for dealing with this new environment. With the shortening of life cycle and time to market this has to evolve with a pace that approaches a need for its real time creation [27].

For example, the internet brings critical new functionalities to enterprises by real time business dynamics and relations. If they don't constantly improve the process of managing this, they would quickly become paralyzed. Building custom software systems to accomplish it can become so complex that the software requires an 'army' of engineers and consultants to manage it. Small to medium businesses need a way to organize their data on a smaller scale and without the expense of hiring costly consultants or paying for maintenance contracts. The approach of building and 
managing a custom software solution is financially out of reach for small to medium sized companies. Therefore companies are moving to web-based software as it can eliminate the need to purchase and manage computer servers, firewalls and software servers just to run the application.

New communication technologies allow a global interaction like never imagined. Internet evolution, and especially the Web 2.0 [25] opened new opportunities and benefits for SME, given its ease of communication and information dissemination [5]. One of the greatest opportunities was the opening of new online applications of network environments known as social networks [41], [4], [8]. Today the internet presents itself as the platform of greater access, in which millions of individuals daily enter at any place or time [40]. In this context, new environments appeared [11] such as the social networking sites like Facebook, YouTube, LinkedIn, Twitter, Hi5, Bebo, MySpace, among others, in which users either communicate or share content [26], [4]. On these platforms people create their profiles, communicate, exchange pictures and data, group on a particular interest creating communities. These individuals, networked, can actively participate in innovation, wealth creation and socialeconomic development in a way never imagined before [28].

According to the study "Internet use in Portugal 2010" [39] more than 60\% of social networks users in Portugal consider important that companies have a profile on these networks. The continuous entry of firms in these applications can completely change the way of doing business. Some authors have suggested that after the knowledge economy and digital economy, a new economy happens now, naming it "Socialnomics" [28] or "Economy of relations" [30], or "Economy of integrity" [3]. The key features of business and innovation, which in past decades were tangible, are now replaced by intangible assets such as knowledge, confidence and relations. Companies need to adapt to this revolution in order to be competitive.

\section{The Alignment Issue}

In Portugal, the enterprises (most of them small or medium sized) invest little in information system's departments due to their limited capacity (financial and organizational). A form of innovation in which they could invest consists of building an entrepreneurial culture supported by a good information structure. There are systems and architectures that can easily contribute to it, based on tools like CRM (Customer Relationship Management), CMS (Content Management Systems), ERP (Enterprise Resource Planning) and SNA (Social Networks Analysis). Integrated into well planned platforms, they can accelerate the implementation of new ideas, products/services and business processes (or improvement of existent ones). Given their enormous potential and online scale, which in some cases can lead to a reconfiguration of the whole organization or business model, entrepreneurs should not only know well this kind of platforms but also be involved at the very beginning of their strategic planning [19].

Managers take most of their decisions based on a considerable amount of data to know what products they should offer, in what quantity, from which supplier, in which way of distribution, to which location, etc. Today, as internet plays an 
increasing role in doing business, firms are using more analytical tools through data warehouse management and social networks. These tools can be specially used in systems designed for data and process integration. ERP systems do this work, however there is some resistance to adopt them related with time of adaptation and change of the existent systems. This can be long and firms generally avoid interrupting their normal activities to start those changes [43]. Thus many are migrating to cloud computing for benefiting from the ease of its online integration. This technology is helping firms virtually manipulate all aspects of the business chain.

Differently from departmentalized solutions, those clouds are transversal as they cross several levels, activities and agents. They make information flow in a simpler way through multiple layers to be extensively shareable. This allows managers to easily get more, diverse and accurate data without needing physical servers. Operations are well coordinated, providing a global view of processes and information flows [21]. In departmentalized systems, on the contrary, there is much data fragmentation which brings the proliferation of complex and expensive relations, as information systems are separated by areas. Today's challenges require consolidating all the data and eliminating complex relations, with a positive impact on process efficiency and business performance.

Integrating CRM function with social networks, consisting of analytical procedures for customer relationship management, makes possible to consolidate information from different sources and communication channels. Firms can use those data to know about their image, improve their products and services, acquire new clients, personalize their offers, etc. CRM techniques allow selecting key information by different points of view, helping to create unique services and critical innovations. However there is the problem, related with people alignment, that employees using these tools are not generally familiar with the criteria inherent to CRM and social networks analysis, which require specific training [43]. The enterprises should consider the adoption and diffusion of new tools from a strategic point of view and evaluate them as any other investment. For instance, many firms don't know how to consolidate several databases to extract information into management decision reports. Instead, they depend on external outsourcing or consulting services which generally increase their costs. To know all the costs and benefits, including the indirect (hidden) ones, the enterprise should define a business plan and, aligning it with the information system, evaluate regularly its results within that plan.

A comparison among small and medium firms in different sectors of the Algarve region (especially in commerce and services), revealed some issues to be considered on aligning new information technologies with business performance. Most of the enterprises interviewed on their threats and opportunities (Swot Analysis) don't align their vision of business with the potential of new information technologies and people competences [14]. In other words, analyzing how opportunities can solve weaknesses (or which threats could become opportunities) they do not fully explore how information technologies could reevaluate these issues. Main factors disturbing this alignment are the lack of an enterprise-wide business view and the rapid rate of technological change. Other authors have also acknowledged these aspects in their studies, such as [29].

Nevertheless, some of the firms interviewed actively align their business vision with the potential of information technologies, namely those from technological 
sectors and commerce chains, which perceive the alignment issue enhancing their performance in terms of process integration, management efficiency, time and completeness of response to customers. Two main reasons are related with this behavior: the nature of their business processes and the right capacity for it. This mainly happens with firms in technological sectors due to their specialized knowhow, and in commerce chains due to their organizational capacity [14]. The presence of technology professionals and their proximity to managers is fundamental, requiring a profile that catches the emergent trends adjusting them to the right pace [33].

Another issue assessed by this case comparison was that the sectors with more mobile activities (such as INEM medical-emergency, CTT post-offices and ALGAR eco-points), as well as the banking sector which increasingly depend on knowledge about financial markets in real time, recognize the growing potential of online and mobile platforms [13]. The ease of mobility achieved, apart from firm's location, allow accessing updated information between its intranet and the mobile gadget in use. Having this aspect in mind, besides the additional potential of online integration, the alignment issue is either a key for business performance, or a key for enterprise knowledge-base. Figure 1 illustrates this point through the main lines of information systems' development, and supporting technologies, with the resulting knowledgebase enhancement:

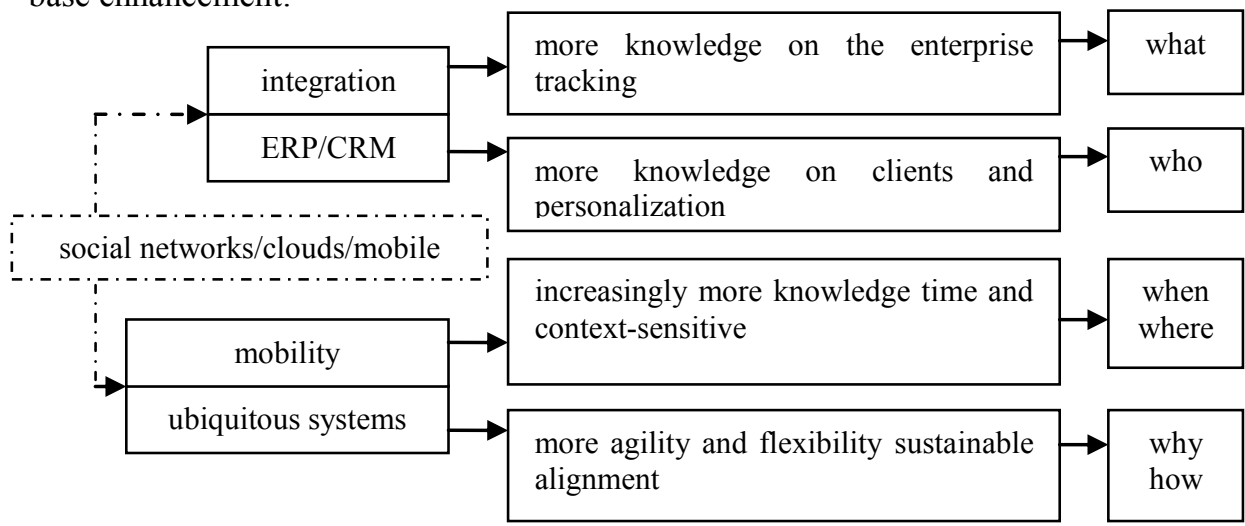

Fig. 1. Main lines of information systems' development and supporting technologies, and resulting advances in enterprise knowledge-base. Source: own elaboration.

The previous statement is not surprising as information analysts and CIO (Chief Information Officers) strongly recognize the increasing support of these architectures to process alignment and knowledge-base improvement, for more real-time decisions and activities [44], [36]. A knowledge structure can then be derived to support matching between business needs and innovations [32]. According to [16], knowledge management is the critical layer to incorporate in enterprise management. According to [37], with the growth of global service economy leading to a huge increase in daily interactions with specialized online services, approaches should combine knowledge management with service architectures aimed at capturing the advances in emerging systems. The following empirical study opens a door for the potential of social networks for SME's performance and knowledge-base. 


\section{An Empirical Study}

Studies on social networks have expanded, receiving increased attention from the scientific community [4]. These platforms are currently a major research focus in several areas. One example is the Facebook application, which has been studied by [10], [1], [20], [38], etc. It is essential to explore the potential of social networks in enhancing the performance of SME as these are generally the most affected by strong global competitiveness. This work aims at characterizing the representation of Portuguese SME, especially of the Algarve region, in these networks and analyzing the activities most potentiated. Some firms use these networks for marketing activities however they should not view social networks as just an online marketing tool [11]. They need to look deeper and analyze these new environments with a multiple perspective as social networks allow communication that covers millions of different features and potential customers [42], [40], [5], [8].

The main objective of this study is to analyze the potential of social networks as tools for SME's development and then indicate a methodological approach for general application. Other works, from [2], [7] and [34], also have analyzed factors and gains related to the use of social networks by SME. It then intends to verify which activities of SME in the Algarve region are already being enhanced by these platforms. For this purpose, an online questionnaire was activated and answered by 70 firms from the region. From the many resulting data, an analysis of the corresponding variables served to identify the most relevant ones and derive some patterns (clusters) according to the level of firms' involvement in social networks.

\subsection{Sample and Methodology}

The methodological path began with an observation of facts related with the subject, through a comparison of social networking sites and the representation/participation of SME in these, as well as how companies benefit from such involvement. For example, comparing several available videos, presentations and discussion groups on social networks. Then, we analyzed several other empirical studies already carried out, which are mentioned in the previous section. This was followed by a selection of techniques for gathering information for data analysis. First, a questionnaire was prepared to collect the data from a sample of SME in the Algarve region. The data were then analyzed through quantitative techniques which include preliminary descriptive statistics and behavioral patterns. Specifically, we used the Categorical Principal Component Analysis (CATPCA) to detect patterns of association between variables [15], [9], [22], [24]. Then, we used the hierarchical cluster analysis based on the Ward method [31] as the criterion to detect patterns of association between firms, considering the variables highlighted by the CATPCA analysis. There are other authors that also combined these two methods of analysis such as [35].

Generally, the questionnaire directed to the SME of Algarve (QSME) aims to characterize the types of SME according to their participation in social networking sites. The questionnaire was built using a specialized online tool - SurveyMonkey (www.surveymonkey.com) - which allows design a website where the questionnaire is available. The use of this tool in research allows quick access to questionnaires, 
facilitating faster responses. An e-mail with the study intentions and a link to the questionnaire was sent to the SME. The data remain in a database, grouped by response [23]. As a sample, we considered $70 \mathrm{SME}$ of the Algarve region having completed the questionnaire and answered it on time. Expecting for more cases would take much time as companies often don't have time to respond to free questionnaires. After closing the online questionnaire, the data were collected to be analysed. The responses directly given in the SurveyMonkey were exported to Excel, and then to SPSS v.17 for more advanced analyses.

\section{Analysis of Patterns}

The purpose of this analysis is to reach to a diagnosis of most relevant variables on the participation of SME in social networks. Thus, we used a Categorical Principal Component Analysis [15], [9], [22], [24] as an exploratory technique of interdependence and reduction of data dimensions in order to detect patterns of association among variables. This analysis allowed to obtain rather consistent results as described in Table 1 .

Table 1. Model summary. Source: SPSS 17.0.

\begin{tabular}{lll}
\hline Dimension & Cronbach's alpha & Variance obtained \\
1 &, 899 & 8,353 \\
2 &, 774 & 4,139 \\
Total &, 940 & 12,492 \\
\hline
\end{tabular}

According to the Cronbach's alpha coefficient, indicator of the degree of internal consistency of observations, our sample is highly consistent in both dimensions (with a total of $94 \%$ ). The related literature informs that this occurs when the coefficient exceeds 70\% [15], [9], [22], [24]. We also can observe from Table 1 that the explained variance is $66.86 \%$ in the 1 st dimension and $33.13 \%$ in the 2 nd dimension.

The CATPCA also revealed the weights of the variables. Figure 2 illustrates the bidimensional structure of variables' distribution on the reference space, in which the vectors project the variable loadings.

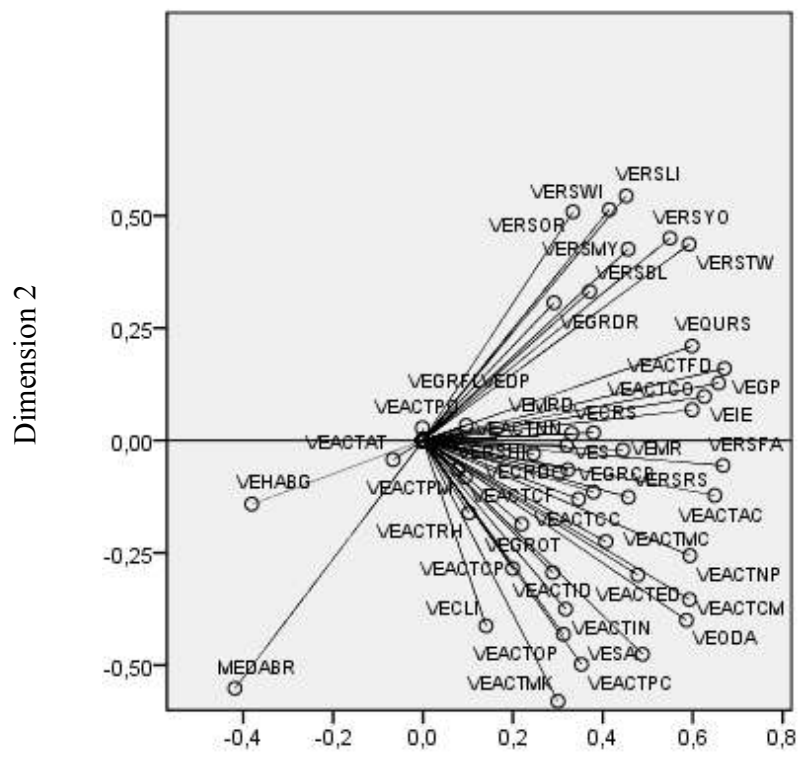

Dimension 1 
Fig. 2. Bidimensional distribution of variables. Source: SPSS 17.0.

From this analysis, all the variables had positive weights in the first dimension while the second dimension had a strong contrast of negative and positive weights. This means there are weak relations between the variables in second dimension, turning it more fragile. The analysis of the most relevant variables (12 relevant in the first dimension and 4 relevant in the second dimension) could derive the two following types or dimensions of social networks (Table 2).

Table 2. Dimensions of relevant variables (types of social networks). Source: own elaboration from the CATPCA analysis using SPSS 17.0.

\begin{tabular}{ll}
\hline Dimension/type & Characteristics \\
\hline $\begin{array}{l}\text { First dim.: social networks for } \\
\text { knowledge and for product- } \\
\text { client interaction }\end{array}$ & $\begin{array}{l}\text { Twitter, Youtube - more oriented to (re)search, } \\
\text { communication and knowledge (professional-oriented); and } \\
\text { Facebook - more oriented to the interaction with customers } \\
\text { (new products to customers, opinions: social-oriented) }\end{array}$ \\
$\begin{array}{l}\text { Second dim.: social networks } \\
\text { with potential for marketing }\end{array}$ & $\begin{array}{l}\text { Orkut, Wikis, LinkedIn - more oriented to marketing and } \\
\text { divulgation }\end{array}$ \\
\hline
\end{tabular}

Based on Table 2, the first dimension retains much more information as it captures the largest percentage of explained variance (Table 1). The second dimension retains less information and captures the residual variance [15], [31]. One aim of the analysis is to reduce the dimensionality of data with the least possible loss of information. Although extracting dimensions some information is lost, the use of all dimensions would complicate the analysis. The main goal is to extract patterns, detected from the explained variance while the remaining observations turn into residual. Thus, the 1st dimension (social networks for knowledge and product-client interaction) is well characterized in Table 2, considering that all its relevant variables have positive weights. The 2nd dimension, due to its most relevant variable being negative (VEACTMK) and related with marketing activities, we named it as social networks with "potential" for marketing (Table 2). Another reason for this classification (mainly the term potential) is the weakness of relations between the variables in the 2nd dimension, as mentioned before.

Experts in e-business and social media emphasize that there is not sufficient empirical work in Portugal to support the dimensions and objectives described in Table 2 [12]. There are discussion groups, such as the "Social network/media strategy" and "Social media Portugal" in LinkedIn, where these aspects are discussed. However, they are limited to opinions from who usually work in these areas, but without sustainable empirical support.

Then, a hierarchical cluster analysis was conducted, based on the Ward clustering method. It detected three different clusters [31]. The three clusters correspond to firms' behavioral patterns according to their involvement with social networks, expressed in the related variables. Considering the relevant variables, and the statistical significance given by CATPCA analysis, the clusters were classified according to the level of SME's involvement in social networks (Table 3). 
Table 3. Clusters of firms (behavioral patterns). Source: own elaboration using SPSS 17.0.

\begin{tabular}{|c|c|}
\hline Clusters obtained & Characteristics \\
\hline $\begin{array}{l}\text { Cluster 1 - "Social } \\
\text { Net Level } 1 " \text { - } \\
\text { formed by } 37 \text { SME, } \\
\text { which mostly: }\end{array}$ & $\begin{array}{l}\text { - lack participation in Wikis, Orkut, Facebook, Twitter, LinkedIn, } \\
\text { Youtube; } \\
\text { - don't use social networks for enhancing their business performance; } \\
\text { - don't implement an integrated strategy with social networks; } \\
\text { - have a positive opinion on social networks' potential for business } \\
\text { performance; } \\
\text { - have a weak social networks' activity regarding marketing, new } \\
\text { products, fidelization and behavioral patterns analysis; } \\
\text { - have a significant social networks' activity regarding communication } \\
\text { with customers; } \\
\text { - don't have a group responsible for the representation/participation in } \\
\text { social networks; } \\
\text { - in average, they use social networks once a weak. }\end{array}$ \\
\hline $\begin{array}{l}\text { Cluster } 2 \text { - "Social } \\
\text { Net Level } 2 " \\
\text { formed by } 21 \text { SME, } \\
\text { which mostly: }\end{array}$ & $\begin{array}{l}\text { - have a significant presence on Facebook; } \\
\text { - usually use social networks for enhancing their business } \\
\text { performance; } \\
\text { - have a strong social networks' activity regarding new products and } \\
\text { communication with customers; } \\
\text { - have a strong dissemination practice through social networks and a } \\
\text { widespread positive opinion on social networks' potential for business } \\
\text { performance; } \\
\text { - in average, they use social networks every day. }\end{array}$ \\
\hline $\begin{array}{l}\text { Cluster } 3 \text { - "Social } \\
\text { Net Level } 3 "- \\
\text { formed by } 12 \text { SME, } \\
\text { which mostly: }\end{array}$ & $\begin{array}{l}\text { - lack participation in MySpace and Wikis; } \\
\text { - have a significant presence on Twitter, LinkedIn, and Youtube; } \\
\text { - generally implement an integrated strategy with social networks; } \\
\text { - have a strong social networks' activity regarding behavioral analysis; } \\
\text { - have a group responsible for firm's representation/participation in } \\
\text { social networks; } \\
\text { - in average, they use social networks several times a day. }\end{array}$ \\
\hline
\end{tabular}

Thus, the clusters obtained evolve in an ascending order of business involvement with social networks as shown by the cluster analysis in Table 3.

\section{Discussion and Implications}

The involvement of SME with social networks in Algarve is not uniform. This research identified three different clusters (groups) named as: 'Cluster Social Net Level 1', 'Cluster Social Net Level 2' and 'Cluster Social Net Level 3'. This classification is due to a different pattern in terms of degree of involvement in social networks. The firms in the first cluster present the lowest involvement with these platforms. Nevertheless, a company in cluster 1 is not necessarily lagging behind a company of cluster 2 as the different degree means a different pattern of involvement (not a pattern of performance). For example, both clusters 2 and 3 have companies 
with significant presence in social networks; however firms in cluster 3 already measure the potential gains, having an integrated strategy with these tools and using them several times a day.

We also found two dimensions of social networks' use: a first dimension oriented either to product-client interaction (Facebook - social oriented) or to knowledge/ research (Twitter, YouTube - professional oriented); and a second dimension with potential for marketing/divulgation (LinkedIn, Wikis, Orkut). So, the first dimension includes two main uses: social and professional. For example, it is enormous the influence that an opinion about a firm's service, widespread in a social network like Facebook, can have on that firm's image (contagion/imperceptible effects).

On the other hand, the second dimension showed weak associations between relevant variables. Thus, our sample is less likely to actively use social networks for marketing strategic integration, despite having propensity for it. For example, the online CRM application (Customer Relationship Management) seems to be on a starting stage for the majority of SME in Algarve ${ }^{1}$. This issue requires a more proactive 'social media' strategy. The steps towards it should include: tracking the links along nodes (connection points) through social network analysis; exploring the resulting experiences/communities; and aligning with all critical partners in the necessary development areas [1].

\section{Conclusions}

Most companies have just been overwhelmed with the flood of data created by networking technologies/communities. This includes click-stream data, detailed email data and also the information thrown off by the enterprise systems' transition [17]. It is interesting that by individually studying this information carefully, firms can have better knowledge of customers and products' trends, quality and defects. The field of business intelligence has been tapping into this explosion of data which is important in dealing with the alignment challenge.

Facing the increasing number of online applications with high potential for integration and mobility, the SME of Algarve already recognize it given their positioning in social networks and business clouds. However, they still lack a well defined strategy, aligned and internationalized. The relevance of aligning their information systems with people and activities continues to intensify and is normally the core of discussion on performance, especially related with the support provided by new technologies. Facing the increasing geographical scope and time-sensitiveness of services, that support is making the difference. For instance, when social networks penetrate all activities and institutions, many aspects of management and organizational structure will change radically. The speed and extent of connectivity they allow enables the creation of new business processes. Bearing in mind those challenges, a company should be able to correctly evaluate benefits and costs among which many are intangible. It is fundamental to define a plan in due course and assess,

\footnotetext{
${ }^{1}$ Especially SME in the technological sector, like Algardata and Visualforma, and some hotels assisted by them, are using the online cloud CRM 'Sales Force' (www.salesforce.com).
} 
on a regular basis, the results obtained from the information systems strategically aligned with external challenges and internal competences.

The data collected for this work showed that the most performed activities through social networks are: communicating with customers, being closer to potential customers and marketing. Nevertheless, SME are also using social networks for activities such as analyzing their competitors and behavioral patterns, knowing trends, cooperation, fidelization, internationalization, new products launching, new brands/ businesses, opinion searching, new ideas, and recruitment. Most of managers consider that social networks enhance the performance of their firms, but few really measure the results from this impact. Firms that most frequently accede to social networks are those whose manager has higher qualification level. And the SME that most use these platforms in Algarve are from the services and hotel/restaurant/bar sectors.

Social networks should be seen as work facilitators, and entrepreneurs need to better understand how to take advantage of their use and provide results for companies. Some advantages to be emphasized are: 'constant' ( 24 hours a day); 'global' (internet as support) and 'in real time' (direct/immediate). These are critical attributes for creating flexible and distinctive outcomes. However, some studies [18], [6] strongly indicate that the most important issue is not being present in large social networks (or in several of them), but to define a 'social media' strategy. Entrepreneurs must be familiar with the existing types of social networks, their characteristics and potential, in order to determine in which to be present and take full advantage. Then, they should start by taking the steps discussed in the previous section.

\section{References}

1. Acquisti, A. and Gross, R. (2006) Imagined communities: Awareness, information sharing, and privacy on the Facebook. Accessed: 03/02/2011. In URL: $<\mathrm{http} / / /$ www.heinz.cmu.edu/ acquisti/papers/acquisti-gross-facebook-privacy-PETfinal.pdf $>$.

2. Amo, M., Constantinides, E. and Romero, C. (2010) Profiles of social networking sites users in the Netherlands. University of Twente Publications. Accessed: 10/03/2011. In URL: $<$ http://doc.utwente.nl/73399/>.

3. Bernasek, A. (2010) The economics of integrity. Editora Harperstudio.

4. Boyd, D. and Ellison, N. (2007) Social network sites: Definition, history, and scholarship. Journal of Computer-Mediated Communication, 13(1), article 11. Accessed: 20/02/2011. In URL: <http://jcmc.indiana.edu/vol13/issue1/boyd.ellison.html $>$.

5. Brandão, R. and Marques, B. (2010) The impact of web 2.0 in the informal learning of the Portuguese SME. AIP-CE, CEPCEP, Universidade Católica Portuguesa.

6. Brandão, M. (2011) O que são redes sociais verticais e horizontais. Accessed: 12/02/2011. In URL:<http://www.maiswebmarketing.com/o-que-sao-redes-sociais-verticais-e-horizontais/>

7. Carr, R., Castleman, T., Mason, C. and Parker, C. (2010) Factors affecting SME's willingness to share knowledge on-line: A path model. Proceedings of the 23rd Bled eConference eTrust on Implications for the individual, enterprises and society. University of Maribor, Bled, Slovenia.

8. Constantinides, E., Lorenzo, C. and Gómes-Borja, M. (2008) Social media: A new frontier for retailers? European Retail Research, 22, 1-27.

9. De Leeuw, J. (1990) Multivariate analysis with optimal scaling, in Gupta, S. e Sethuraman, J. (Eds.) Progress in Multivariate Analysis. Calcutta: Indian Statistical Institute. 
10.Dwyer, C., Hiltz, C. and Passerini, K. (2007) Trust and privacy concern within social networking sites: A comparison of Facebook and MySpace. America's Conference on Information Systems (AMCIS), USA

11.Evans, D. (2009) Marketing de media social, uma hora por dia. Editora AltaBooks.

12.Falcão, H. (2010) Social technology. Accessed: 15/02/2011. In URL: $<$ http://pt.scribd.com/collections/2545330/Social-Technology-Tecnologia-Social>.

13.Fernandes, S. (2012) Main differentiating issues in aligning information systems with business performance. International Journal of Information Systems in the Service Sector, IGI Global (forthcoming)

14.Fernandes, S. (2010) Critical information as a success factor in organizations: objective and methodological approach. CIEO Spatial and Organizational Dynamics Discussion Papers, 2, 69-82.

15.Gifi, A. (1990) Nonlinear multivariate analysis. New York: J. Wiley \& Sons.

16.Gudas, S. (2008) Enterprise knowledge management aspects and layers. Paper presented at the 12th World Multi-Conference on Systemics, Cybernetics and Informatics, Florida, USA.

17.Hopkins, M. (2010) The 4 ways IT is driving innovation. An interview with Erik Brynjolfsson. Accessed: April 24. In URL: <http://sloanreview.mit.edu/themagazine/articles/2010/spring/51330/it-innovation-brynjolfsson-article/>.

18.Inesting (2011) Social media marketing. Accessed: 12/02/2011. In URL: $<\mathrm{http}$ ://www.inesting-search.com/SMM/social-media-estrategia.html $>$.

19.Kearns, G. and Sabherwal, R. (2006) Strategic alignment between business and information technology: A knowledge-based view of behaviours, outcome and consequences. Journal of Management Information Systems, 23(3), 129-162.

20.Lampe, C., Ellison, N. and Steinfeld, C. (2007) Profile elements as signals in an on-line social network. Conference on human factors in computing systems. San Jose, CA, USA.

21.Laudon, C. and Laudon, J. (2004) Management information systems: Managing the digital firm. New Jersey, USA: Prentice Hall.

22.Meulman, J. (1992) The integration of multidimensional scaling and multivariate analysis with optimal transformations of the variables. Psychometrika, 57, 539-565.

23.Minayo, M., Suely F. and Gomes, R. (2007) Pesquisa social, teoria, método e criatividade. Brasil: Petrópolis.

24.Nishisato, S. (1994) Elements of dual scaling: An introduction to practical data analysis. New Jersey: Lawrence Erlbaum Associates, Inc.

25.O'Reilly, T. (2005) What is web 2.0: Design patterns and business models for the next generation of software. Accessed: 09/04/2011. In URL: $<$ http://www.elisanet.fi/aariset/Multimedia/Web2.0/What\%20Is\%20Web\%202.doc>.

26.Pei, M., Ramayah, T. and Suki, N. (2011) Factors enhancing employed job seekers intentions to use social networking sites as a job search tool. International Journal of Technology and Human Interaction, 7(2), 38-54.

27.Philipson, S. (2008) A specification of an environment for modern product development. Paper presented at the International Conference on Advances in Management, Boston, USA.

28. Qualman, E. (2009) Socialnomics - Como os media sociais estão a mudar o mundo como vivemos e como fazemos negócios. Editorial Presença.

29.Rathnam, R. (2004) Alignment of business strategy and IT strategy: A case study of a fortune 500 financial services company. The Journal of Computer Information Systems, $45(2), 1-8$.

30.Robison, L. and Ritchie, B. (2010) Relationship economics: The social capital paradigm and its application to business, politics and other transactions. Editora Gower.

31.Romesburg, H. (1984) Cluster analysis for researchers. USA: Lifetime Learning Publications. 
32.Rosselet, U., Jolliet, Y. and Wentland, M. (2009) Knowledge management for IT project portfolio. Paper presented at the 10th European Conference on Knowledge Management, Vicenza, Italy.

33.Setti, A. and Fernandes, S. (2007) The role of the information system's manager in the organization. Interscienceplace, 1(3), 1-10.

34.Silver, D. (2009) The Social network business plan: 18 strategies that will create great wealth. New Jersey: John Wiley \& Sons.

35.Sousa, L., Galante, H. and Figueiredo, D. (2003) Qualidade de vida e bem-estar dos idosos: um estudo exploratório na população portuguesa, Revista Saúde Pública, 37 (3), 364-371.

36.Spewak, S. and Hill, S. (1992) Enterprise architecture planning: developing a blueprint for data, applications and technology. USA: John Wiley \& Sons Inc.

37.Spohrer, J. and Kwan, S. (2009) Service science, management, engineering, and design (SSMED): an emerging discipline - outline \& references. International Journal of Information Systems in the Service Sector, 1(3), 1-31.

38.Stutzman, F. (2006) Student life on the facebook. Accessed: 20/02/2011. In URL: $<$ http://ibiblio.org/fred/facebook/stutzman_fbook.pdf $>$.

39.Taborda, M. (2010) A utilização da internet em Portugal 2010. LINI - Lisbon Internet and Networks International Research Programme. Lisboa.

40.Tapscott, D. and Williams, A. (2007) Wikinomics, a nova economia de multidões inteligentes. Editora Quidnovi.

41.Tredinnick, L. (2006) Web 2.0 and business: A pointer to the intranets of the future. Business Information Review, 23(4), 228-234.

42.Vasconcelos, V. and Campos, P. (2010) Distributed informal information systems for innovation: An empirical study of the role of social networks, in Varajão, J. et al. (Eds.), Enterprise Information Systems. Part II CCIS 110, Springer-Verlag, 208-217.

43.Vasilev, J. and Georgiev, G. (2003) Tendencies in the development of ERP systems. Paper presented at the International Conference on Computer Systems and Technologies, Varna, Bulgaria.

44.Zachman, J. (1987) A framework for information systems architecture. IBM Systems Journal, 26(3), 276-292. 